\title{
A rare case of perivascular epithelioid cell tumor (PEComa) of the greater omentum

\author{
Koichi Okamoto ${ }^{1 *} \mathbb{D}$, Yuka Okada', Kohei Ohno', Takahiro Yagi', Mitsuo Tsukamoto', Takuya Akahane', \\ Ryu Shimada', Tamuro Hayama', Takeshi Tsuchiya', Keijiro Nozawa', Keiji Matsuda', Tsuyoshi Ishida², \\ Fukuo Kondo ${ }^{2}$ and Yojiro Hashiguchi ${ }^{1}$
}

\begin{abstract}
Background: A tumor composed exclusively or predominantly of human melanin black 45 (HMB45)-positive epithelioid cells is called a perivascular epithelioid cell tumor (PEComa). We report a very rare case of a PEComa of the greater omentum.

Case presentation: MRI conducted to examine the orthopedic disease of the patients, a 49-year-old Japanese woman, also identified a tumor in her pelvis. A CT scan revealed a tumor mass on the right side of the pelvic floor and clear nutrient vessels originating from the splenic and celiac arteries. An omental primary tumor or accessory spleen was thus suspected, and tumor resection was performed. The tumor was a light brown solid tumor with a smooth margin, measuring $5.2 \times 3.8 \times 3.5 \mathrm{~cm}$. Histopathologically, the tumor was composed mainly of spindle and epithelioid cells, and large and small blood vessel formation was observed. In the immunohistochemical staining, tumor cells were positive for human melanin black 45 (HMB-45) and Melan-A and partially positive for alpha-smooth muscle actin. The final diagnosis was PEComa of the greater omentum.
\end{abstract}

Conclusions: Although omental PEComa is very rare, it should be considered as a differential disease of an omental primary tumor.

Keywords: Perivascular epithelioid cell tumor, PEComa, Human melanin black 45, HMB45, Omental primary tumor, Angiomyolipoma, Omental PEComa

\section{Background}

A perivascular epithelioid cell tumor (PEComa) is a rare mesenchymal tumor composed of epithelioid cells characterized by histological and immunohistochemical evidence of both smooth muscle and melanocytic differentiation [1]. In immunohistochemical staining, the melanocyte marker HMB-45 (human melanin black 45) is the most sensitive (92\% positive); Melan-A is the next most sensitive. The smooth muscle marker smooth muscle actin (SMA) is found in $80 \%$ of PEComas [2]. PEComas have been reported to occur at various sites such as gynecologic sites, ureter, intestinal tract, bone, and skin [2-6]. However, there are few reports of primary omental PEComa.

\footnotetext{
* Correspondence: okamo@kk.iij4u.or.jp

'Department of Surgery, Teikyo University School of Medicine, 2-11-1 Kaga Itabashi-ku, Tokyo 173-8605, Japan

Full list of author information is available at the end of the article
}

Although primary tumors of the greater omentum are rare, there are several reports of malignant tumors of this type [7]. Therefore, in the treatment of an omental primary tumor, the preoperative differential diagnosis is important, and it is necessary to consider PEComa as one of the differential diagnoses. Here, we describe a rare case diagnosed as an omental PEComa postoperatively.

\section{Case presentation}

A 49-year-old Japanese woman underwent an MRI examination in the referring hospital for an assessment of the orthopedic disease of her right hip joint, and the MRI revealed a tumor in her pelvis. She was referred to our hospital, where an MRI examination again showed tumor mobility (Fig. 1), and a tumor derived from the intestinal tract was suspected.

In the contrast CT image (Fig. 2), a mass approx. $45 \mathrm{~mm}$ in size was found on the right side of the pelvic floor, and 


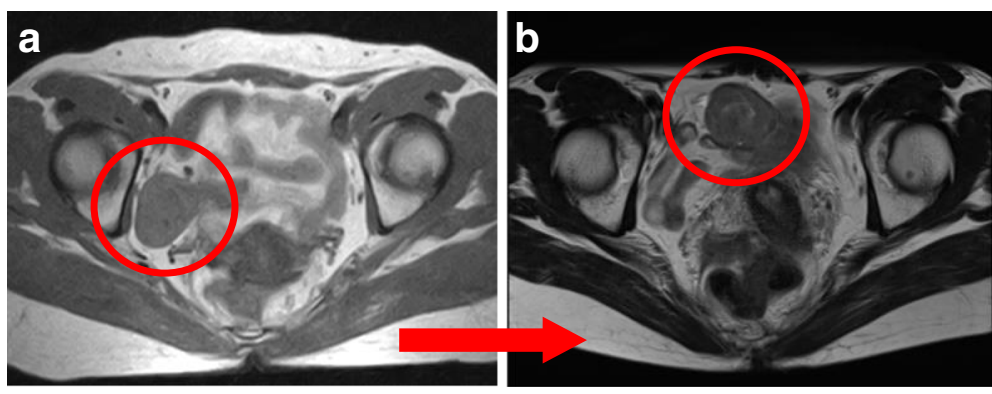

Fig. 1 Preoperative pelvic T1-weighted MRI findings. A tumor mass of $37 \mathrm{~mm}$ in size was found in the pelvis, and a mobile lesion in the peritoneal cavity was observed by comparing the image taken at the referral hospital (a) with the image taken at our hospital (b). The tumor appeared at a mildly higher signal than the muscle

in the blood vessel construction image, the tumor was nourished by vessels from the splenic artery to the greater omentum. In ${ }^{18} \mathrm{~F}$-fluoro-2-deoxyglucose positron emission tomography/computed tomography $\left({ }^{18} \mathrm{~F}-\mathrm{FDG}-\mathrm{PET} / \mathrm{CT}\right)$, no abnormal accumulation was observed (Fig. 3). The results of complete blood cell counts and biochemical tests were all normal. Cancer antigen 19-9 (CA19-9) showed a mild elevation at $37.8 \mathrm{U} / \mathrm{mL}$ (normal range $<37.0 \mathrm{U} / \mathrm{mL}$ ), and carcinogenic embryonic antigen (CEA) was normal at $0.8 \mathrm{ng} / \mathrm{mL}$ (normal range $<5.0 \mathrm{ng} / \mathrm{mL}$ ). Based on all of these results, the preoperative diagnosis was a suspected omental primary tumor or accessory spleen.

There was a danger of torsion irrespective of the presence or absence of malignancy, and the patient desires surgery to remove the tumor; the surgery was conducted concurrently with the diagnosis and treatment. The surgery was a single-incision laparoscopic-assisted greater omental tumor resection. A longitudinal incision was made approx. $4 \mathrm{~cm}$ around the umbilicus. A multichannel port (x-Gate ${ }^{\circ}$, Sumitomo Bakelite, Tokyo) was inserted in the wound. Observation of the abdominal cavity revealed a red and solid tumor mass of approx. $4 \mathrm{~cm}$. Adhesion with the surrounding tissue was not observed. The greater omentum and the tumor were guided out of the body through the gate hole (Fig. 4a), and the tumor was excised together with the greater omentum. The tumor, a light brown tinged solid mass with a smooth border, was $5.2 \times$ $3.8 \times 3.5 \mathrm{~cm}$ in size with a well-defined border (Fig. 4b).

Histopathologically, the tumor involved large and small blood vessels (Fig. 5a), and tumor cells with eosinophilic cytoplasm were increased in number, in sheet form (Fig. 5b). In immunohistochemical staining, the tumor cells were found to be positive for HMB45 (Fig. 5c), Melan-A (Fig. 5d), and $\alpha$-SMA (Fig. 5e), but negative for CD34, Desmin, c-kit, and s-100.

Based on the above results, the tumor was diagnosed as an omental PEComa. There has been no recurrence at 16 months after the surgery.

\section{Discussion}

The image findings of primary PEComa have been reported to be nonspecific [8]. In this patient's case, we considered
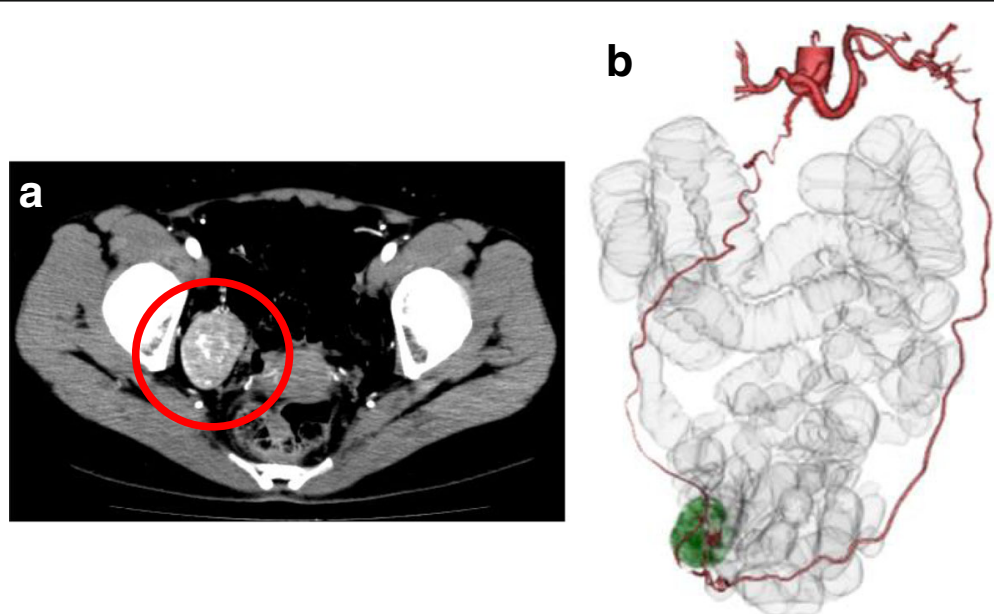

Fig. 2 Contrast-enhanced CT image findings. a A 45-mm-large tumor mass on the right side of the pelvic floor. Inhomogeneous mineralization which was somewhat borderless was recognized inside. $\mathbf{b}$ Clear nutrient vessels originating from the splenic artery were considered omentum branches 


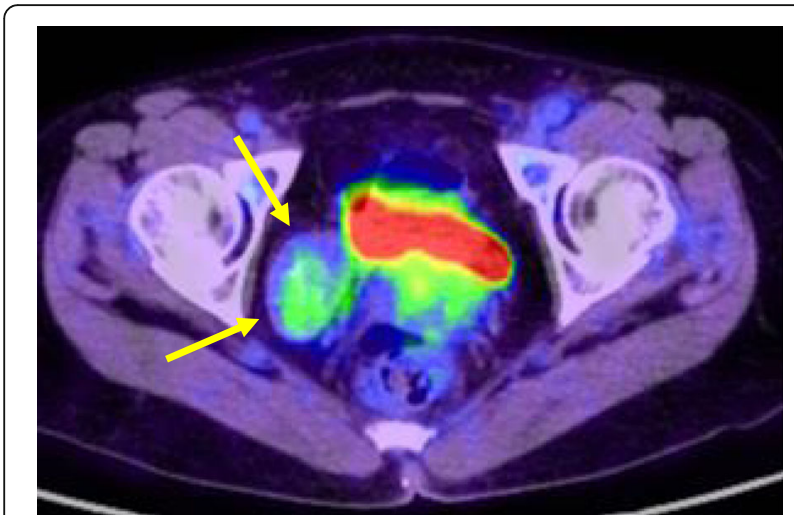

Fig. $3^{18}$ F-fluoro-2-deoxyglucose positron emission tomography/ computed tomography ( $\left.{ }^{18} \mathrm{~F}-\mathrm{FDG}-\mathrm{PET} / \mathrm{CT}\right)$ finding. The SUV max of the tumor was 2.56 in the early phase and 2.49 in the late phase, and no abnormal accumulation in the tumor (yellow arrow) was observed

omental liposarcoma, PEComa, teratoma, and accessory spleen as the preoperative diagnosis, considering the MRI findings and partial calcification in CT. Omental tumors have been reported to cause torsion [9-11]. Indeed, in our patient's case, the possibility of twisting was considered because the preoperative diagnosis of omental PEComa was difficult and because the approx. 5-cm tumor was located at the tip of the greater omentum, which also presents a risk of torsion of the omentum. The surgery was thus carried out concurrently with the patient's diagnosis and treatment.

Omental PEComas are very rare. To the best of our knowledge, only two prior cases of omental PEComa or perivascular epithelioid cell tumor have been reported. Our literature search using PubMed with "omental PEComa" or "omental perivascular epithelioid cell tumor" as keywords revealed that only one case of omental PEComa was reported between 1950 and 2018; the case was an omental angiomyolipoma reported by Takamura et al. [12]. That case was quite different from our patient's because multiple angiomyolipomas coexisted in the liver. In addition, the case previously received right nephrectomy and enucleation of the left kidney for angiomyolipomas of both kidneys 11 years ago. Another case could not be retrieved by PubMed search with the above keywords, but the case was included in the 26 perivascular epithelioid cell neoplasm cases reported by Folpe et al. [2]. However, details are unknown. Our case is the first single PEComa of the greater omentum.

Laparoscopic surgery is less invasive compared with open surgery [13-16]. In addition, umbilical single-incision laparoscopic surgery (SILS) is cosmetically superior to open surgery [17]. As a malignant PEComa that caused intraperitoneal seeding has been reported in the past, it is necessary to firmly search the abdominal cavity during surgery [18]. For these reasons, in a mobile omental tumor, it is a good indication of SILS. In our case, SILS was chosen because the patient emphasized the cosmetic result of the wound. This is the first report of omental PEComa excised by SILS which is cosmetic and enables simultaneous observation in the abdominal cavity and tumor resection.

Since PEComa is a rare disease, there are few reports on criteria of malignancy, but in 2005, Folpe et al. proposed a classification that divides PEComa from benign to malignant into three categories: benign, uncertain malignant potential, and malignant (Table 1) [2]. According to the classification, our patient's case applies only to a factor of "size $>5 \mathrm{~cm}$," so it can be considered as "uncertain malignant potential." Our patient has been recurrence-free for 16 months since the surgery, as confirmed by CT follow-up.
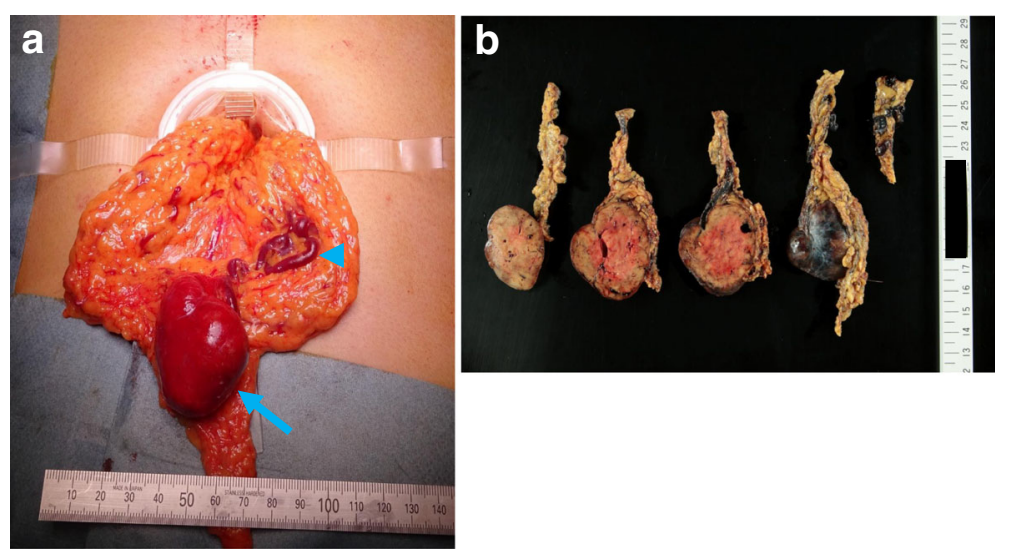

Fig. 4 a Intraoperative finding. Greater omentum and omental tumor induced outside the body. About $5 \mathrm{~cm}$ large omental tumor (arrow) and nutrient blood vessel (arrowhead) inside the greater omentum. b Resected specimen. A light brown solid tumor with a clear and smooth border with a size of $5.2 \times 3.8 \times 3.5 \mathrm{~cm}$ 


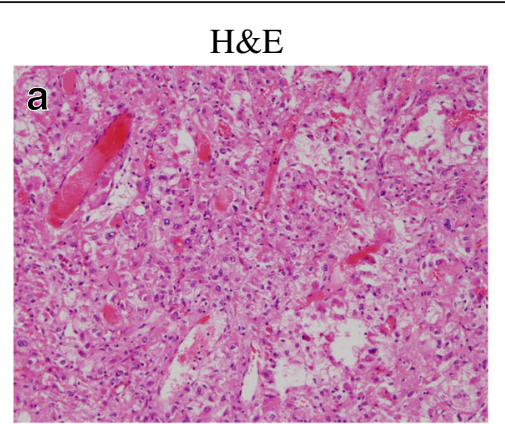

HMB45

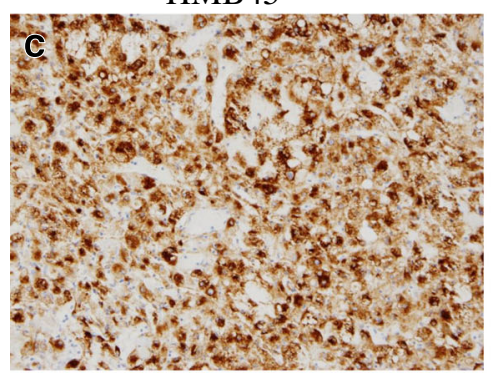

a-SMA

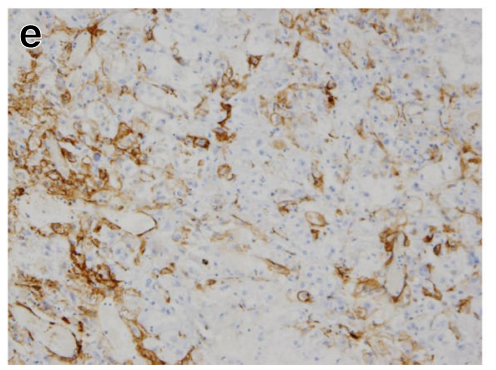

$\mathrm{H} \& \mathrm{E}$

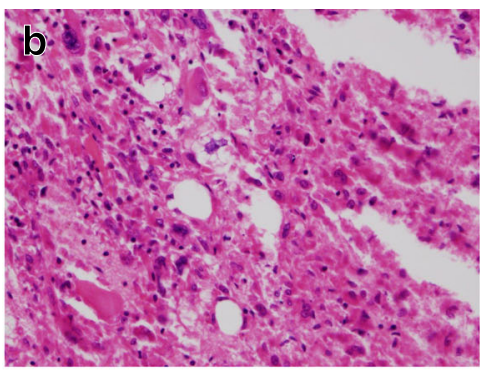

Melan-A

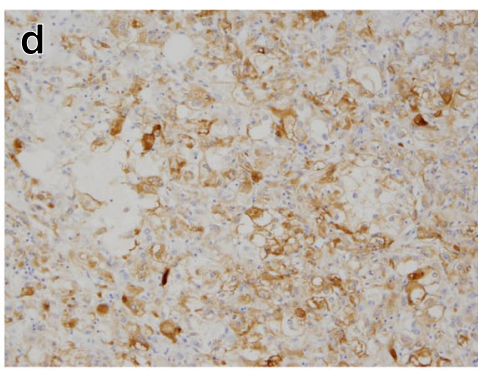

Fig. 5 Histopathological findings. a, b Hematoxylin and eosin (H\&E) staining photomicrographs. Immunohistochemical staining photomicrographs for $\mathbf{c}$ HMB45, d Melan-A, and e a-SMA. Photomicrographs were taken under $\mathbf{a} \times 20$ objective and a $\times 10$ ocular lens ( $\mathbf{a}, \mathbf{c}$, $\mathbf{d}$, e) and under $\mathrm{a} \times 40$ objective and $\mathrm{a} \times 10$ ocular lens $(\mathbf{b})$

Table 1 Classification of PEComas proposed by Folpe et al

\begin{tabular}{llll}
\hline & Benign & $\begin{array}{l}\text { Uncertain malignant } \\
\text { potential }\end{array}$ & Malignant \\
\hline Criteria & $\begin{array}{l}\text { No worrisome } \\
\text { features }\end{array}$ & $\begin{array}{l}\text { Nuclear pleomorphism/ } \\
\text { multinucleated giant } \\
\text { cells only }\end{array}$ & $\begin{array}{l}\text { Two or more } \\
\text { worrisome } \\
\text { features }\end{array}$ \\
& Size $<5 \mathrm{~cm}$ & or & Size $>5 \mathrm{~cm}$ \\
Non-infiltrative & Size $>5 \mathrm{~cm}$ only & Infiltrative \\
Non-high & & High nuclear \\
nuclear grade & & grade and \\
and cellularity & & cellularity \\
Mitotic rate & & Mitotic rate \\
$\leqq 1 / 50 H P F$ & & N1/50HPF \\
No necrosis & & Necrosis \\
No vascular & & Vascular \\
invasion & & invasion \\
\hline
\end{tabular}

\section{Conclusions}

We presented the case of a primary greater omental PEComa with uncertain malignant potential in a 49-year-old woman. Although omentum PEComas are very rare, omental tumors following a malignant course must be treated correctly and should be considered a differential diagnosis.

\section{Acknowledgements}

We are grateful to the patient for allowing us to use her medical records in our case report.

\section{Availability of data and materials}

Data are available on request due to privacy.

\section{Authors' contributions}

$\mathrm{KO}$ was involved with the concept and design of this manuscript. KO, YO, TY, $M T, T A, R S, T H, T T, K N$, and KM contributed as a gastrointestinal surgeon in operative performance and perioperative treatment. TI and FK had contributed as tumor pathologist. YH supervised the report. All authors read and approved the final manuscript. 


\section{Ethics approval and consent to participate}

It is approved by the ethics committee of Teikyo University (approval date, 23 August 2016, registration number; 16-032).

\section{Consent for publication}

Written consent was obtained from the patient for publication of this case report and any accompanying images. A copy of the written consent is available for review by the Editor-in-Chief of this journal.

\section{Competing interests}

The authors declare that they have no competing interests.

\section{Publisher's Note}

Springer Nature remains neutral with regard to jurisdictional claims in published maps and institutional affiliations.

\section{Author details}

'Department of Surgery, Teikyo University School of Medicine, 2-11-1 Kaga Itabashi-ku, Tokyo 173-8605, Japan. ${ }^{2}$ Department of Pathology, Teikyo

University School of Medicine, Tokyo, Japan.

Received: 7 March 2018 Accepted: 6 June 2018

Published online: 19 June 2018

\section{References}

1. Thway K, Fisher C. PEComa: morphology and genetics of a complex tumor family. Ann Diagn Pathol. 2015;19:359-68.

2. Folpe AL, Mentzel T, Lehr HA, Fisher C, Balzer BL, Weiss SW. Perivascular epithelioid cell neoplasms of soft tissue and gynecologic origin: a clinicopathologic study of 26 cases and review of the literature. Am J Surg Pathol. 2005:29:1558-75.

3. Sukov WR, Cheville JC, Amin MB, Gupta R, Folpe AL. Perivascular epithelioid cell tumor (PEComa) of the urinary bladder: report of 3 cases and review of the literature. Am J Surg Pathol. 2009;33:304-8.

4. Doyle LA, Hornick JL, Fletcher CD. PEComa of the gastrointestinal tract: clinicopathologic study of 35 cases with evaluation of prognostic parameters. Am J Surg Pathol. 2013;37:1769-82.

5. Yamashita K, Fletcher CD. PEComa presenting in bone: clinicopathologic analysis of 6 cases and literature review. Am J Surg Pathol. 2010;34:1622-9.

6. Liegl B, Hornick JL, Fletcher CD. Primary cutaneous PEComa: distinctive clear cell lesions of skin. Am J Surg Pathol. 2008;32:608-14.

7. Ishida H, Ishida J. Primary tumours of the greater omentum. Eur Radiol. 1998:8:1598-601.

8. Tirumani $\mathrm{SH}$, Shinagare $\mathrm{AB}$, Hargreaves J, Jagannathan JP, Hornick JL, Wagner AJ, Ramaiya NH. Imaging features of primary and metastatic malignant perivascular epithelioid cell tumors. AJR Am J Roentgenol. 2014 202:252-8

9. Y G, R A: Omental torsion. J Clin Diagn Res 2014, 8:NE01-NE02.

10. Kinjo Y, Adachi Y, Seki K, Tsubono M. Laparoscopic resection for torsion of an omental lipoma presenting as an acute abdomen in a 5-year-old girl. J Surg Case Rep. 2014;7:rju072.

11. Lee KH, Song MJ, Jung IC, Lee YS, Park EK. Autoamputation of an ovarian mature cystic teratoma: a case report and a review of the literature. World J Surg Oncol. 2016;14:217.

12. Takamura K, Miyake H, Fujii M, Nishi M, Tashiro S, Shimada M. Multiple hepatic angiomyolipomas with a solitary omental angiomyolipoma. J Med Investig. 2005;52:218-22.

13. Veldkamp R, Kuhry E, Hop WC, Jeekel J, Kazemier G, Bonjer HJ, Haglind E, Pahlman L, Cuesta MA, Msika S, et al. Laparoscopic surgery versus open surgery for colon cancer: short-term outcomes of a randomised trial. Lancet Oncol. 2005:6:477-84.

14. Fujii S, Tsukamoto M, Fukushima Y, Shimada R, Okamoto K, Tsuchiya T, Nozawa K, Matsuda K, Hashiguchi Y. Systematic review of laparoscopic vs open surgery for colorectal cancer in elderly patients. World J Gastrointest Oncol. 2016;8:573-82.

15. Zheng L, Ding W, Zhou D, Lu L, Yao L. Laparoscopic versus open resection for gastric gastrointestinal stromal tumors: a meta-analysis. Am Surg. 2014;80:48-56

16. Chi JL, Xu M, Zhang MR, Li Y, Zhou ZG. Laparoscopic versus open resection for gastric gastrointestinal stromal tumors (GISTs): a size-location-matched case-control study. World J Surg. 2017;41:2345-52.
17. Katsuno G, Fukunaga M, Nagakari K, Yoshikawa S, Azuma D, Kohama S. Short-term and long-term outcomes of single-incision versus multi-incision laparoscopic resection for colorectal cancer: a propensity-score-matched analysis of 214 cases. Surg Endosc. 2016;30:1317-25.

18. Yamamoto H, Oda Y, Yao T, Oiwa T, Kobayashi C, Tamiya S, Kawaguchi K, Hino O, Tsuneyoshi M. Malignant perivascular epithelioid cell tumor of the colon: report of a case with molecular analysis. Pathol Int. 2006;56:46-50.

\section{Ready to submit your research? Choose BMC and benefit from:}

- fast, convenient online submission

- thorough peer review by experienced researchers in your field

- rapid publication on acceptance

- support for research data, including large and complex data types

- gold Open Access which fosters wider collaboration and increased citations

- maximum visibility for your research: over $100 \mathrm{M}$ website views per year

At BMC, research is always in progress.

Learn more biomedcentral.com/submissions 